\title{
Estratégias enunciativas de subversão da espacialidade nos jogos eletrônicos Portal, Antichamber e Monument Valley
}

\author{
Ana Silvia Lopes Davi Médola' \\ http://orcid.org/0000-0003-2101-3727
}

Bruno Jareta de Oliveira'

http://orcid.org/0000-0002-2598-6940

I - UNESP

Bauru (SP), Brasil

Resumo: As estratégias enunciativas de projeções espaciais não referenciadas no mundo natural presentes em jogos eletrônicos são o objeto de análise deste trabalho. Sob a perspectiva da semiótica discursiva e estudos da linguagem audiovisual, busca-se compreender as lógicas de produção de sentido nas projeções espaciais dos jogos Portal, Antichamber e Monument Valley. As análises indicam que as imagens sintetizadas ampliam e subvertem a lógica perspectivista na representação da espacialidade e engendram regras de jogabilidade a partir de uma homologação parcial entre os regimes de interação do espaço enunciado com o do espaço da enunciação.

Palavras-Chave: enunciação espacial; linguagem audiovisual; meios digitais; jogos eletrônicos.

Abstract: Enunciative strategies of subversion of spatiality in the electronic games Portal, Antichamber and Monument Valley. The enunciative strategies of spatial projections not referenced in the natural world that are present in electronic games are the object of analysis in this work. From the perspective of discursive semiotics and audiovisual language studies, the goal is to understand the production of meaning logics in the spatial projections of the Portal, Antichamber and Monument Valley games. The analyzes indicate that the synthesized images amplify and subvert the perspectivist logic in the representation of spatiality and generate playability rules based on a partial homologation between the interaction regimes of the enunciated space with the space of the enunciation.

Keywords: spatial enunciation; audiovisual language; digital media; electronic games. 


\section{Introdução}

A maneira como o público se relaciona com as narrativas audiovisuais tem sofrido significativas mudanças em função dos mecanismos de interação incorporados nos processos comunicacionais recentes. Jogos nos quais o destinatário pode abrir e atravessar portais que saltam de um espaço a outro sem uma coerência já assimilada ou então navegar por ambientes distintos que coexistem no mesmo espaço são exemplos de ações em obras contemporâneas que acionam de forma intensa a percepção sensível, estésica, na fruição de conteúdos decorrentes de uma textualização sintetizada, possibilitada pelos dispositivos digitais, em enunciados que subvertem a dinâmica dos arranjos enunciativos consolidados na linguagem audiovisual analógica no século passado. Nesse sentido, o ponto de interesse do presente estudo recai sobre a comunicação mediada pelos actantes da enunciação nas interações possibilitadas pelas projeções do espaço; espaço este notadamente descolado da referencialidade do mundo natural, promovendo uma ênfase na percepção sensível em relação à inteligível no processo de apreensão do sentido.

Entender os mecanismos enunciativos de jogos eletrônicos é relevante, pois, como aponta Murray (2003), as produções para ambientes digitais devem considerar a produção de sentido decorrente da arquitetura desses meios. O questionamento manifestado pela autora (2003, p.179) sobre a necessidade de os produtores criarem histórias ricas e satisfatórias, explorando as propriedades características de ambientes digitais e proporcionando os prazeres estéticos que o meio nos promete, parece estar se concretizando na indústria dos jogos eletrônicos. Sobre o processo de textualização, Fiorin (1991, p. 458) lembra que os diferentes arranjos enunciativos dependerão das coerções da semiótica empregada para manifestar o discurso. Nesse sentido, é necessário conhecer as especificidades do meio expressivo onde a linguagem se desenvolve.

Sob a perspectiva da semiótica discursiva e estudos da linguagem audiovisual e meios digitais, este trabalho investiga a categoria enunciativa espacial e seus modos de significação em produções audiovisuais contemporâneas. O estudo está estruturado em quatro seções. Na primeira será revisado o conceito de enunciação espacial e, em seguida, o processo de projeção desta categoria enunciativa nas representações visuais. Serão discutidas, na segunda seção, as questões relacionadas às maneiras de apreensão do espaço, para que os resultados encontrados nesta e na seção anterior subsidiem as reflexões da terceira sobre a representação de relações espaciais não convencionais em obras audiovisuais. Em seguida, na quarta seção, os três jogos que compõem o corpus deste estudo serão analisados: Portal, lançado em 2007 e produzido pela Valve Corporation; Antichamber, de 2013 e produzido pela Demruth; e Monument Valley, de 2014, produzido pela Ustwo. Todos são jogos de soluções de enigmas e foram selecionados por introduzirem na sua jogabilidade regras com representações espaciais não referenciadas no mundo natural, responsáveis pelos processos de significação. 


\section{Enunciação espacial no audiovisual}

A enunciação é uma instância pressuposta à existência do próprio enunciado independente do sistema semiótico no qual se manifeste - e é nela que se instauram, por meio de um conjunto de procedimentos, as categorias de pessoa, tempo e espaço. Compreender esses procedimentos evidencia as estratégias do texto. Em As astúcias da enunciação, Fiorin (1996) pontua que os estudos dedicados a compreender o espaço nos discursos verbais são majoritariamente destinados a entender sua semântica (ou seja, os investimentos de sentidos), mas pouco se discute sobre sua sintaxe. Para o autor, o motivo é que, comparado às outras duas categorias, tempo e pessoa, o espaço teria menor relevância no processo de discursivização, já que a linguagem verbal permite que falemos sem informar qualquer indicação espacial, enquanto é impossível deixar de projetar tempo e pessoa.

Estendendo para o audiovisual a postulação de Fiorin (1996, p. 261) sobre a necessidade de compreender as estratégias enunciativas de projeção da categoria do espaço no enunciado, para perceber os efeitos de sentido da experiência de espacialidade presente no texto, consideramos impositivo ponderar sobre o modo de projeção do espaço nas linguagens visuais. Isto porque, em tais formas de representação, não se pode operar com a mesma premissa apontada por Fiorin (1996) de que nos discursos as indicações espaciais são facilmente omitidas. A natureza da própria representação imagética já está associada a um reconhecimento de algo do mundo natural e, consequentemente, à identificação (ou não identificação) visual do espaço. Ao tratar a figuratividade nos dispositivos visuais, Greimas (2004, p. 80) esclarece que:

\footnotetext{
O exame mais acurado do ato de semiose mostraria bem que a principal operação que o constitui é a seleção de certo número de traços visuais e sua globalização, é a apreensão simultânea que transforma o feixe de traços heterogêneos num formante, vale dizer, numa unidade do significante que pode ser reconhecida, quando enquadrada no crivo do significado, como a representação parcial de um objeto do mundo natural .
}

Dessa forma, parte-se do pressuposto de que, em se tratando de representações visuais figurativas, o reconhecimento da espacialidade está pautado na macrossemiótica do mundo natural. Isto se aplica também à análise de obras abstratas, pois abstração e iconização não são maneiras diferentes de representação, e sim graus variáveis da figuratividade (BERTRAND, 2003). A projeção espacial é, neste sentido, constitutiva da representação visual. Mesmo a projeção de um ponto que se manifesta à visão, independentemente de qualquer referência, está inscrita em um espaço. Esta categoria enunciativa está presente, portanto, em qualquer representação visual, mesmo quando não identificável pelo crivo de leitura do mundo natural. 
Antes mesmo da invenção da primeira câmera fotográfica, autores das pinturas e gravuras de diferentes épocas e localidades desenvolveram sistemas de representação que projetavam em suas obras visuais os objetos do espaço a partir de diferentes técnicas de perspectiva (MACHADO, 1984). As invenções da fotografia e do cinema permitiram a automatização tanto do registro quanto da reconstituição do visual. Machado (1984, p. 5) afirma que "toda uma tecnologia produtora de imagem figurativa vem sendo desenvolvida e aperfeiçoada há pelo menos cinco séculos, no sentido de possibilitar uma reprodução automática do mundo visível".

De acordo com Couchot (1993), a imagem, que nos meios analógicos é criada a partir da captação de luz proveniente de um objeto do mundo natural, passa a ser gerada, no computador, por meio de representações numéricas. Segundo o autor, uma nova ordem visual entrou em vigor, e, neste contexto, artistas que buscam novas experiências podem contar com poderosos meios de criação em suas produções. Um desses atributos destacados por Couchot (1993) é que, nesta nova lógica de figuratividade visual, é possível agir sobre a imagem numericamente simulada, alterando dados e parâmetros em tempo real. Manipulações que anteriormente eram realizadas de maneira analógica (exposições químicas e usos de lentes e espelhos assimétricos, por exemplo) ganham novas perspectivas graças às edições matemáticas dos dados digitais. Os jogos eletrônicos estão inseridos nesse mesmo contexto, pois o mundo ali simulado não foi captado de objetos do mundo natural. A câmera virtual pela qual é possível enxergar o universo projetado não é um dispositivo de captação que registrou luz, e sim uma entidade matemática. O que ela exibe são instruções numéricas que não são, necessariamente, obrigadas a emular condições físicas do mundo natural.

Verifica-se que esta possibilidade de propor novas visualidades pode ampliar os modos de fruição do objeto. Ao tratar de uma das características dos ambientes digitais, a participação, Murray (2003) destaca que espaços desenhados para reagir às informações que inserimos são atraentes, pois nos convidam à interação. A autora afirma que os meios lineares "retratam espaços tanto pela descrição verbal quanto pela imagem, mas apenas os ambientes digitais apresentam um espaço pelo qual podemos nos mover" (MURRAY, 2003, p. 84). Para além de um fazer interpretativo do espaço, a participação associada à navegação cria a condição fundamental para que o espaço seja "vivido" por um corpo instaurado no texto e manipulado pelo enunciatário. O espaço é experienciado e não apenas visto.

Essas novas lógicas de articulação abrem possibilidades para que novas relações entre destinatário e espaço possam acontecer nos ambientes espaciais simulados. Os arranjos enunciativos constroem discursivamente esse ambiente, a fim de cumprir os objetivos do fazer comunicativo. Ao investigar esse novo estatuto, faz-se necessário entender primeiramente como a dinâmica que envolve sujeitos e espaço opera no mundo natural, para, num segundo momento, buscar compreender os procedimentos de enunciação nas produções audiovisuais que subvertem a racionalidade da representação do espaço pautada na semiótica do mundo natural. 


\section{Apreensão do espaço e as relações de sentido}

Stephen Hawking (2001) adverte, no livro O universo numa casca de noz, que o tempo e o espaço não costumam ocupar nossas reflexões mais basilares, mas que em algum momento da vida nos perguntamos o que é o tempo, quando ele começou e aonde ele nos leva. Fazemos essas mesmas perguntas sobre o espaço? Como definir o que é o espaço?

O estudo das propriedades físicas da matéria nos permite entender o funcionamento do espaço e seus elementos, e nossa experiência cotidiana nos ensina a deduzir fenômenos possíveis e não possíveis. Mesmo com consciência de que, a partir das contribuições de Albert Einstein, tempo e espaço são entendidos na ciência contemporânea como relativos, podemos afirmar que, em nossa experiência espacial com o mundo, imperam os postulados de Isaac Newton:

Todas as partes do espaço, na física newtoniana, são simultâneas num mesmo instante. E o tempo, por sua vez, é compreendido como a sucessão de instante a instante da totalidade do espaço. Há um só tempo, um tempo absoluto, na física de Newton e também um só espaço, um espaço absoluto, que se atualiza por inteiro a cada virada de um instante no seguinte (TASSINARI, 2006, p. 159).

Greimas e Courtés (1979) concebem o espaço a partir do pressuposto de que ele é produzido e consumido por sujeitos e, por isso, é apreendido a partir de qualidades sensíveis, como as visuais, táteis, acústicas etc. Os autores enfatizam a característica tridimensional da espacialidade. Para eles, essa concepção deve ser levada em conta, uma vez que o sujeito é produtor e consumidor de espaço. No caso dos jogos digitais, é pela propriocepção - que, de acordo com Fontanille (2007), é a posição assumida pelo sujeito da percepção - que o destinatário tem a sensação de presença espacial nos ambientes digitais. As qualidades sensíveis espaciais projetadas no enunciado atingem essa capacidade do ser humano de perceber o corpoa diferença é que tanto corpo quanto espaço sentido estão enunciados na tela.

Uma das perspectivas para entender os processos de significação e apreensão do espaço defendidas por Landowski (2015, p. 19) é compreender o mundo como um "tecido", ou seja, como um campo operacional de elementos, e a chave dessa visão é a categoria da "continuidade". O autor pontua que a categoria contínuo/descontínuo também pode ser atribuída às articulações espaciais, e isto auxilia na compreensão do mundo como um plano de coisas contínuas. Neste sentido, o universo se apresenta como uma única imensa isotopia intimamente articulada, e cada elemento oferece regularidades específicas em seu próprio nível, enquanto, simultaneamente, interage tanto com o que contém quanto com o que o engloba. Devem ser consideradas três escalas no fazer analítico de espaços: uma mais ampla, que compreende o objeto espacial analisado como um todo, ou um continuum; outra que observe as descontinuidades, ou partes, deste todo considerado na escala anterior; e uma última que procura entender a lógica capaz de dar conta 
da coesão do conjunto. Uma radical descontinuidade do espaço seria o "abismo", vazio diante do qual há uma sensação de vertigem tanto do corpo como da razão. "Tecido" e "abismo" são dois conceitos que circunscrevem modos de apreensão do espaço, conforme formulado por Landowski (2015, p. 25) e serão adotados como recursos analíticos neste estudo.

A partir dessas postulações, pode-se inferir que uma forma de leitura dos sentidos decorrentes da projeção espacial é identificar suas unidades e o modo como estão colocadas em relação. Uma vez compreendidas, elas podem ser pensadas como possíveis de serem replicadas em ambientes visuais simulados e navegáveis, e usadas, consequentemente, de forma criativa na projeção de enunciados. Assim, buscaremos discutir, na sequência, a partir da análise de produções participativas nos meios digitais, de que modo o audiovisual, por meio da montagem, permite que o espectador tenha a experiência de imersão em ambientes que não ocorrem no mundo natural, do ponto de vista espacial.

\section{Novas representações espaciais, novos significados}

As lógicas que regem os corpos dos sujeitos e o espaço do mundo, objeto de estudo sobretudo da Física - e que em termos semióticos podemos atribuir à macrossemiótica do mundo natural - costumam ser replicadas nos universos visuais. Alguns deles, no entanto, extrapolam e modificam algumas leis, apresentando manipulações espaciais inexistentes no mundo natural, criando novas situações de sentidos. Assim, duas formas de incompatibilidades espaciais nas linguagens visuais podem ser identificadas: aquelas do ponto de vista da representação geométrica e aquelas no âmbito da física nelas representadas (PETROVITS; CANOSSA, 2013). As obras do holandês Escher são um ótimo ponto de partida para compreender a primeira delas.

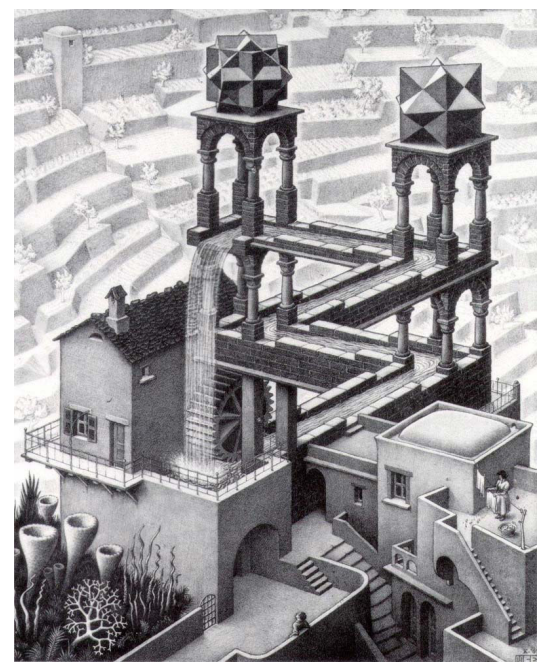

Fig. 1. Queda d'água (1961), de M.C. Escher. Trajeto impossível da água mascarado pela perspectiva isométrica. Fonte: Maurits Cornelis Escher, Queda d'água, 1961, litografia, $38 \times 30 \mathrm{~cm}$. 
Em sua obra intitulada Queda d'água (Figura 1), por exemplo, a projeção espacial produz estranhamentos: um duto de água cujo ponto final, que deveria ser mais baixo, já que a água desceria de acordo com a gravidade, despeja água no ponto inicial, produzindo o efeito de sentido de uma aparente incompatibilidade no trajeto. Esse arranjo visual pode ser classificado como um paradoxo espacial e, para entendê-lo, é preciso conhecer o conceito de perspectiva artificialis. Segundo Machado (1984, p. 53, grifos do autor):

Durante quase cinco séculos, as necessidades figurativas da civilização ocidental foram satisfeitas por um sistema de representação plástica do espaço conhecido como perspectiva artificialis [...]. Esse sistema, nascido e florescido no Renascimento, procurava obter uma sugestão ilusionista de profundidade com base nas leis "objetivas" do espaço formuladas pela geometria euclidiana. Para construir essa perspectiva, ele [Leo Batista Alberti, seu primeiro teorizador] considerava o centro visual como sendo um ponto fixo, correspondente ao vértice da "pirâmide"; em seguida, ligava esse ponto aos contornos de todos os objetos que estavam dentro do campo visual: as linhas retas que efetivavam essa ligação ("raios visuais", na sua terminologia) deveriam determinar no plano de intersecção a posição relativa desses objetos e, portanto, a configuração final das imagens no quadro. Tinha-se assim um sistema geométrico objetivo para projetar todo o espaço tridimensional no plano bidimensional da tela.

Este sistema passou a ser entendido como a representação mais fiel do espaço real visto pelo homem (MACHADO, 1984), e, a partir dele, o observador aprendeu a distinguir a distância e os volumes dos objetos. Figuras como a de Escher adotam um código perspectivo diferente, o do tipo isométrico, que, segundo Machado (1984), é obtido a partir de distorções óticas. Esse efeito confunde a nossa visão habitual e mascara incoerências espaciais, permitindo os paradoxos. Técnicas semelhantes são usadas por artistas na montagem de instalações nas quais o público pode, presencialmente, testemunhar essa ilusão e ter a sensação de estar em um ambiente impossível. Distorções de volumes e ilusão de que elementos estão flutuando (Figura 2) são exemplos de efeitos possíveis a partir de truques de perspectiva visual. Instalações desta natureza ocupam esta primeira forma de representar incompatibilidades espaciais. Monument Valley, um dos jogos que compõe o corpus deste estudo, utiliza o mesmo código de representação visual e, a partir dele, a jogabilidade é possível. Este assunto será retomado nas análises. 


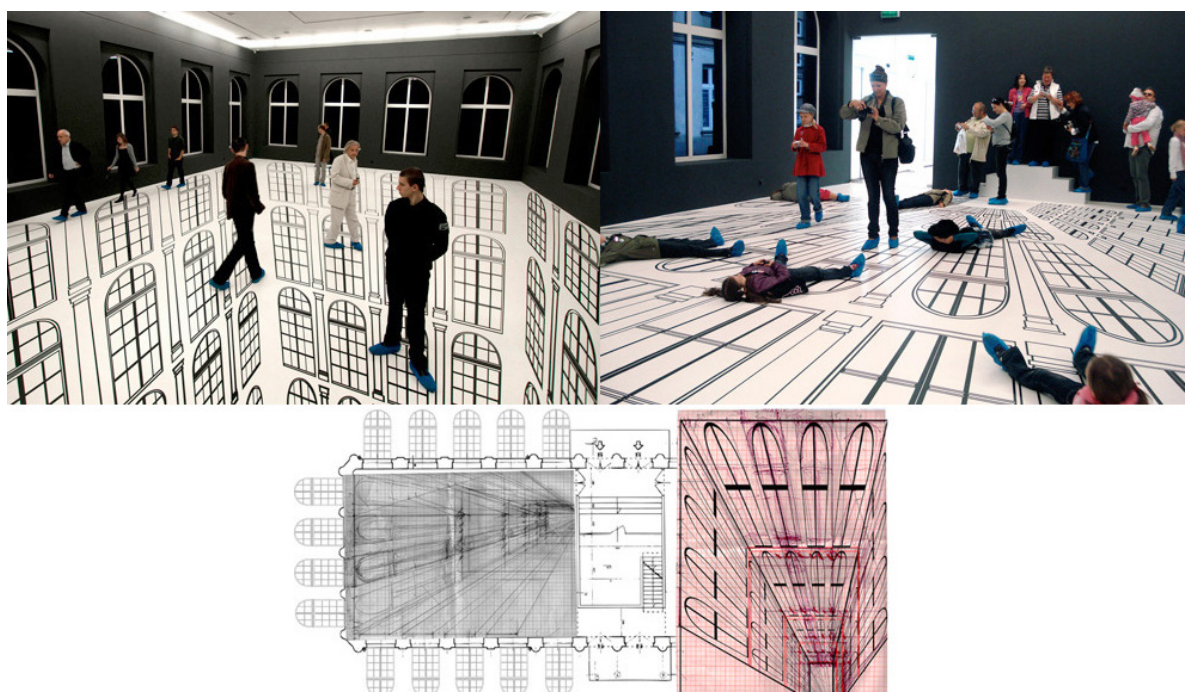

Fig.2. Abyssal (2010), instalação de Regina Silveira. Desenho no chão causa a ilusão, a partir de um ponto de visualização, de que as pessoas estão flutuando. Fonte:Montagem nossa, feita com imagens retiradas do site oficial da artista Regina Silveira ${ }^{1}$.

A incompatibilidade espacial no âmbito da física, segunda forma de projeção que manifesta uma subversão da espacialidade, são aquelas nas quais são representadas organizações de espaços não referenciadas no mundo natural. A experiência nos ensina que é pouco provável que duas coisas ocupem o mesmo lugar no espaço, o que possibilita deduzir que eventos como portais que conectem dois locais diferentes e cômodos que coexistem no mesmo espaço -- situações recorrentes em Portal e Antichamber - são impraticáveis.

O fato de esses eventos não acontecerem no mundo natural não inviabiliza suas representações visuais. Produções audiovisuais convencionais também exploram de diferentes maneiras subversões espaciais em seus enunciados. As obras de Georges Méliès, no início do cinema, são um exemplo. No filme $A$ Sereia² um mágico tira vários itens de dentro de uma cartola, incluindo três coelhos. O clássico truque é feito no filme com cortes que escondem os momentos nos quais os itens foram inseridos entre uma ação e outra, mas o resultado mostra ao público uma cartola com um espaço aparentemente incompatível de abarcar tantos itens, mas, mesmo assim, eles são removidos dali de dentro.

Como afirmado anteriormente, no audiovisual clássico, o espaço apresentado no enunciado é algo visto num carácter distante, enquanto nos jogos eletrônicos a experiência parece extrapolar para um status de experiência vivida. A sensação de não naturalidade espacial é vista pelo destinatário do audiovisual clássico, mas ele não pode interagir naquele ambiente. A diferença é que a participação e a navegação espacial possível por meio das interfaces digitais provocam um efeito de espaço sentido não apenas como um conhecimento daquele ambiente, mas como uma consciência e agência proprioceptiva.

1 Disponível em: <http://reginasilveira.com/ABYSSAL>. Acesso em: 24 ago. 2018.

2 SEREIA, A. Direção: Georges Méliès. França: Star Film Company, 1904. (5 min). 
Tais ambientes participativos têm o potencial de desenvolver habilidades nos destinatários que não são necessariamente acionadas na experiência vivida no mundo natural. Sobre as reflexões acerca das imagens simuladas, Couchot (1993) afirma que "a própria inteligência do homem, sua faculdade de raciocinar, de aprender, talvez sua emotividade (pelo menos de alguns de seus mecanismos) começam a ser modelizadas, programadas. A automatização ganha o próprio pensamento". As obras selecionadas para análise neste estudo encontram-se neste contexto participativo.

\section{Portal, Antichamber e Monument Valley}

Serão apresentados inicialmente, nesta seção, os princípios básicos que regem a jogabilidade dos três jogos, para que, em seguida, sejam desenvolvidas as análises.

Portal dá ao jogador o poder de utilizar uma arma chamada "portal gun". O instrumento permite que o enunciatário crie nas superfícies dos cômodos uma abertura oval do tamanho de uma pessoa. A arma possui dois botões: um dispara uma força que, em contato com uma superfície, abre uma entrada e o outro botão, a saída: se o jogador (ou qualquer outro objeto) passar por uma, sairá por outra (Figura 3). Esta única possibilidade de manipulação garante várias fases do jogo que partem dos enigmas mais simples aos mais complexos.

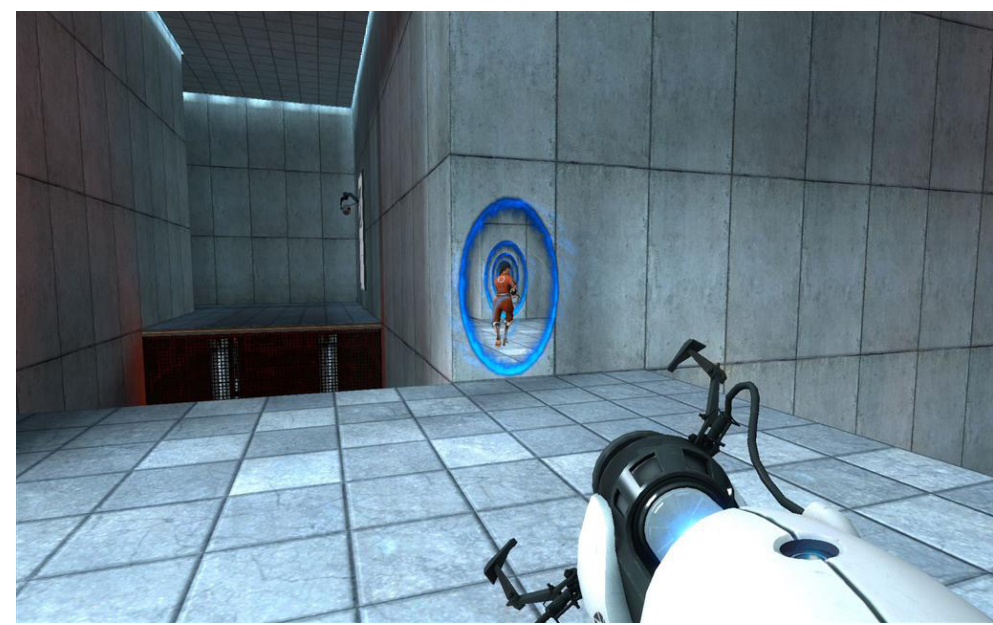

Fig. 3. Personagem vê suas próprias costas, pois abriu um portal na parede da frente e outro na de trás. Fonte: Imagem do jogo Portal.

O segundo jogo, Antichamber, é um labirinto repleto de enigmas que desafiam os referenciais pautados na lógica do espaço do mundo natural. No jogo, os ambientes não seguem as mesmas regras do mundo natural, por exemplo, o segmento no qual 
o enunciatário se depara com duas escadas, uma que leva ao nível superior e outra ao inferior (Figura 4). Independente da escolha, o sujeito acaba retornando para o mesmo lugar, inevitavelmente. A saída (aparentemente simples) pode demorar a ser encontrada: o jogador deve retornar ao mesmo lugar pelo qual veio - neste caso, um novo corredor aparecerá e o conduzirá à saída, e, enquanto progride pelas escadas, isso nunca acontecerá. Talvez seja complicado deduzir essa solução para o enigma, porque, no mundo natural, o espaço por onde passamos costuma ser o mesmo quando retornamos. Momentos assim se repetem durante todo o jogo.

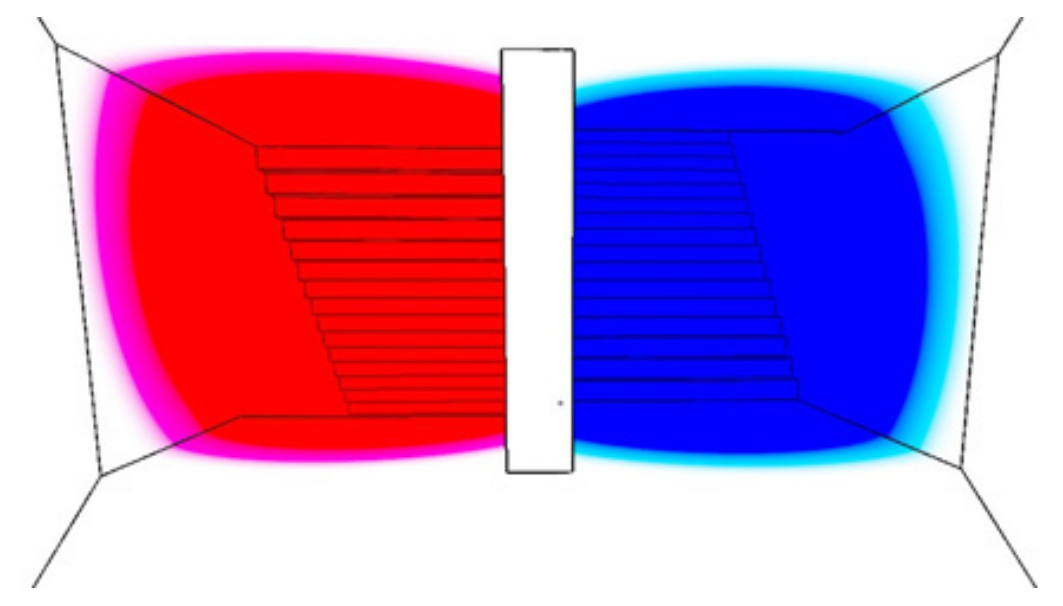

Fig.4. Escadas em um dos enigmas de Antichamber: independente da escolha, o jogador retorna ao mesmo lugar. Fonte: Imagem do jogo Antichamber.

Monument Valley, diferentemente dos dois primeiros jogos selecionados para a análise, não apresenta sua jogabilidade a partir de uma câmera subjetiva -recurso audiovisual que sincretiza o olhar do enunciatário com o do personagem, gerando o efeito de sentido de inserir o público na cena, já que ele passa a ver com os olhos do sujeito presente no espaço enunciado. Também composto por níveis com enigmas, o jogo apresenta uma personagem identificada como uma princesa. À medida que o jogo avança de nível, o jogador deve conduzi-la pelos tortuosos caminhos das obras arquitetônicas que surgem, . Essas construções são apresentadas no código perspectivo isométrico, permitindo que paradoxos espaciais sejam percorridos pela princesa sem que isso fique incoerente visualmente. A manipulação dos fragmentos do cenário é o que garante a jogabilidade, pois sua estrutura deve ser rearranjada para abrir caminho à personagem (Figura 5), e, a cada movimento, o jogador deve buscar aquela configuração visual capaz de conduzi-lo pelo ambiente. 


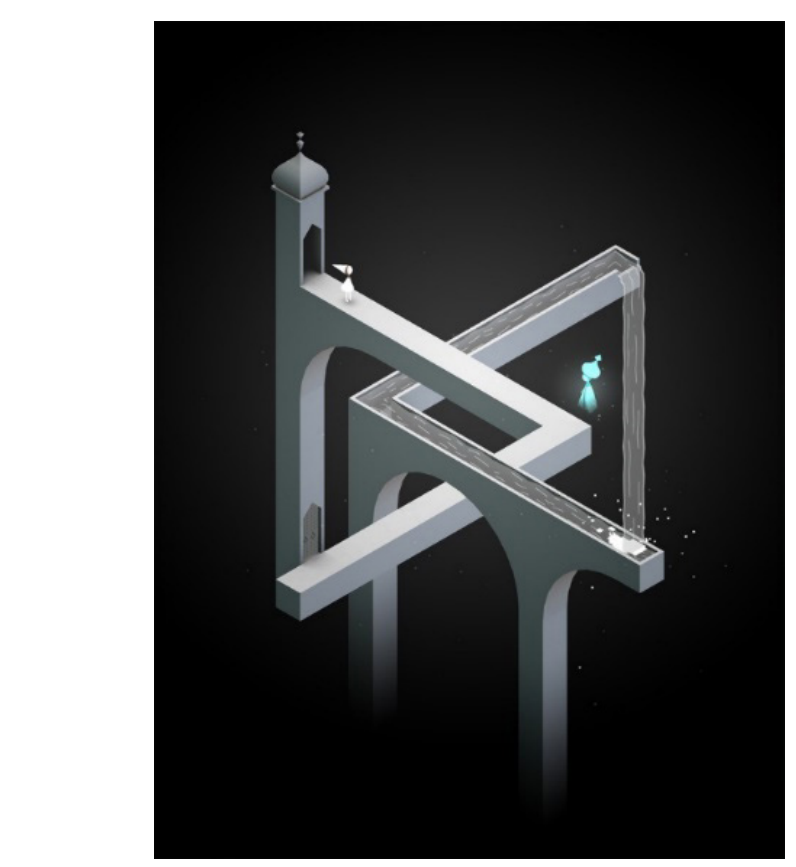

Fig. 5. Um dos enigmas visuais de Monument Valley. O mesmo patamar que a princesa ocupa atinge dois andares diferentes da torre. Fonte: Imagem do jogo Monument Valley.

O conceito de enunciação espacial, a concepção de sujeitos produtores e consumidores de espaço e o entendimento do espaço como "tecido" e "abismo" auxiliarão na compreensão da dinâmica enunciativa destas obras. Os espaços passíveis de serem percorridos e manipulados são criados e desenvolvidos pelos enunciadores levando em consideração a percepção do espaço do enunciatário. O espaço virtual a ser explorado não é algo natural ou acidental: cada ambiente dos jogos foi projetado por um dos sujeitos da enunciação, o enunciador. O jogador, ou seja, o outro actante da relação enunciativa, é o consumidor deste espaço. Ele anda, pula, avança, retrocede, para, espera, movimenta peças etc. A combinação de recursos técnico-expressivos do audiovisual nos meios digitais, como as texturas que revestem as superfícies, os sons emitidos no ambiente condicionados ao movimento do jogador e a manipulação de peças por meio do tato, por exemplo, dão ao espaço produzido qualidades sensíveis. A propriocepção permite "sentir" escalas e dimensões. Estratégias enunciativas conduzem o jogador a uma experiência naquele espaço proposto, semelhante à do espaço do mundo natural, que também pode ser explorado de maneira análoga. Essa semelhança só é possível graças à própria experiência de vida. Quando as ações espaciais desempenhadas no cotidiano coincidem no jogo, o processo de reconhecimento é instantâneo. Os jogos estudados concebem a jogabilidade, no entanto, nos elementos que não são referenciados no mundo natural. 
Como recomenda Landowski (2015), quando trata do espaço como "tecido", ao identificar as partes de um todo e suas relações, é possível entender sua coesão. A estratégia enunciativa de jogos como Portal, Antichamber e Monument Valley é justamente desestabilizar as relações espaciais que já conhecemos da nossa experiência cotidiana, explorando os recursos de participação dos meios digitais. Os arranjos enunciativos rearticulam as unidades espaciais em novas continuidades, provocando os efeitos de vertigem característicos do "abismo", sendo meta do jogador reencontrar a referencialidade habitual ao tecer tais "abismos" no "tecido", ou seja, encontrar a lógica do continuum proposto. Desta forma, torna o espaço um ambiente operacional, que pode não apenas ser percorrido e navegado, mas também manipulado e explorado de maneiras não possíveis fora dos jogos.

No caso de Portal, a simples ação de construir entradas e saídas nas superfícies abre múltiplos caminhos de interação do sujeito com o espaço, e o avanço dos níveis depende disso. Não é possível, no mundo natural, criar uma abertura em uma parede e sair em outra de outra parede posicionada à frente, acima ou no piso, mas o efeito de sentido dessas rupturas espaciais dentro do jogo não se apresenta de difícil compreensão. Uma vez que essa nova regra espacial é assimilada, o jogador passa a modificar o espaço a ser explorado. Tal regra incide nos referenciais de espacialidade que articulam noções de sequencialidade em função dos deslocamentos. Ela subverte as unidades na categoria contínuo/descontínuo. As demais regras dos elementos que compõem esse ambiente permanecem iguais, como, por exemplo, a gravidade: se um primeiro portal for aberto verticalmente em uma parede e outro horizontalmente no teto, o jogador cairá de cima para baixo se progredir pelo portal inicial. Neste aspecto, a categoria vertical/horizontal guarda o referencial do mundo natural.

Em Antichamber, o destinatário deve não só se acostumar às aparentes inconsistências espaciais, se pretende terminar o desafio, mas deve aprender a decifrá-las e encontrar seus funcionamentos, que seguem uma lógica (não a mesma do mundo natural, mas há uma lógica). No caso de Monument Valley, o enunciatário deve antecipar as atualizações possíveis a partir da manipulação das estruturas arquitetônicas por onde a princesa precisa cruzar. Dependendo de suas escolhas, o que em uma configuração é a posição no espaço, passa a ser outra posição mesmo sem que essa parte específica tenha sido alterada as duas possibilidades sugeridas no paradoxo espacial geométrico assumem os caminhos de arranjos da participação.

Observa-se, nas três produções, que o continuum proposto corresponde à totalidade do espaço enunciado, e que o jogo apresenta os recursos disponíveis ao jogador, para que, a partir da propriocepção, ele possa perceber suas descontinuidades e os caminhos que permitam a manipulação dessas unidades a partir da coesão espacial projetada. Em todas, é possível identificar que as características físicas do mundo natural permanecem em seus processos de espacialização. Não há uma total ruptura com o que é conhecido da relação espacial cotidiana. Quando uma regra é suspensa -como, por exemplo, se retornarmos 
por um mesmo caminho talvez o espaço que ali estava seja outro - há a quebra de uma isotopia espacial que corresponde ao mundo experienciado, e a reiteração desta suspensão instaura uma nova isotopia. Essa maneira de manipular os elementos dispostos neste campo operacional abre caminhos para o sujeito se relacionar de diferentes formas com o espaço enunciado, e raciocínio e sensibilidade para progredir no jogo dependem disso.

\section{Considerações finais}

A análise dos procedimentos enunciativos de projeção espacial nos três jogos eletrônicos, tomados como exemplos, reafirma, por um lado, a pressuposição fundante de que a representação visual sempre está associada à projeção espacial, ainda que diferentes técnicas explorem distintas possibilidades de enunciação do espaço. Entretanto, os ambientes digitais que produzem as imagens sintetizadas introduzem novas perspectivas na representação da espacialidade, alterando lógicas relativas às noções de sequencialidade, ligadas à categoria contínuo/descontínuo, assim como às lógicas da topologia, pautadas nas leis que regem as dinâmicas do mundo natural, como as relações de verticalidade/ horizontalidade.

Na linguagem audiovisual, a montagem é o mecanismo de articulação das projeções espaciais, capaz de produzir efeitos de imersão do espectador no ambiente representado, ainda que em posição de contemplação. No entanto, os arranjos enunciativos em Portal, Antichamber e Monument Valley criam universos ficcionais com regras espaciais próprias, que propõem racionalidades de outra ordem, distintas da referencialidade do mundo natural.

Apoiadas nos postulados de Landwoski (2015) sobre os regimes de espaço, as análises destes textos audiovisuais contemporâneos possibilitaram identificar como esses enunciados permitem oferecer ao destinatário experiências que alteram, como aponta Couchot (1993), a própria lógica do pensamento humano - habilidade válida para todos os actantes da enunciação. Isto porque, em função de fatores como o estatuto de simulação da imagem numérica, e a necessidade de agenciamento, o que produz o efeito de sentido de coparticipação do enunciatário na construção destes enunciados característicos das mídias digitais proporciona relações inéditas na projeção do espaço, agora não apenas contemplável. O slogan de divulgação da continuação do jogo Portal - "Now you're thinking with portals" ${ }^{3 \prime}$ - é indicativo desta alteração na forma de pensar o espaço.

Um novo mundo é proposto e não é obrigatório que ele funcione com as mesmas regras do mundo empírico. Por outro lado, uma suspensão total das lógicas espaciais naturais pode dificultar uma assimilação do funcionamento daquele ambiente simulado. Os jogos analisados apontam, portanto, para uma homologação parcial entre as regras do espaço enunciado com as do espaço da enunciação. Abrir portais, modificar os cômodos em função de uma ação indireta ou mudar a arquitetura em detrimento da perspectiva

3 Tradução livre: "Agora você está pensando com portais". 
são exemplos de atividades espaciais incompatíveis na nossa experiência cotidiana e que, inseridas nas obras audiovisuais para os meios digitais, são responsáveis pela emergência de significações a serem construídas. Há uma coerência na projeção do espaço no enunciado que parte das isotopias espaciais do mundo natural, mas novas dinâmicas de relação entre sujeito e espaço são incluídas. Compreender essa coerência faz parte do jogo.

Por fim, é importante ressaltar que novas maneiras de operacionalizar o espaço nas representações digitais ocasionam novas visualidades. Os efeitos de sentido provenientes da navegação e manipulação espacial dos enunciados aqui analisados apontam, como preconizou Murray (2003), para um fazer comunicativo que explore novos caminhos na busca do desenvolvimento da sua forma expressiva. Ao enunciador cabe o papel de conceber um ambiente de fruição e navegação espacial para além das possibilidades do mundo natural. O ato de pensar o espaço como "tecido" e "abismo", nos termos propostos por Landowski (2015), pode ser a chave para que novas relações sejam identificadas e projetadas em um mundo simulado com imagens e sons.

Ana Silvia Lopes Davi Médola é docente do Departamento de Comunicação Social - Curso de Radialismo - e do Programa de Pós-Graduação em Comunicação. É livre-docente em Comunicação Televisual pela Universidade Estadual Paulista (Unesp) e líder do Grupo de Estudos Audiovisuais (GEA).

asilvia@faac.com.br

Bruno Jareta de Oliveira é doutorando em Comunicação pela Universidade Estadual Paulista (Unesp) e membro do Grupo de Estudos Audiovisuais (GEA).

brunojareta@hotmail.com

\section{Referências}

BERTRAND, D. Caminhos da semiótica literária. Bauru: EDUSC, 2003.

COUCHOT, E. Da representação à simulação. In. PARENTE, A. Imagem Máquina: A Era das Tecnologias do Virtual. Rio de Janeiro: Ed. 34, 1993.

FIORIN, J. L. As astúcias da enunciação: as categorias de pessoa, espaço e tempo. São Paulo: Editora Ática, 1996.

FONTANILLE, Jacques. Semiótica do Discurso. Tradução de Jean Cristtus Portela. São Paulo: Contexto, 2007. 
GREIMAS, A.J. Semiótica figurativa e semiótica plástica. Tradução de Assis Silva. In: OLIVEIRA, Ana Cláudia de (Org.). Semiótica plástica. São Paulo: Hacker Editores, 2004. p. 75-96.

GREIMAS, A.J.; COURTÉS, J. Dicionário de semiótica. Tradução de Alceu Dias Lima et al. São Paulo: Contexto, 2008.

HAWKING, S. O universo numa casca de noz. Tradução e Ivo Korytowski. São Paulo: Mandarim, 2001.

LANDOWSKI, E. Regimes de espaço. Galáxia (São Paulo, Online), n. 29, p. 10-27, jun. 2015.

MACHADO, A. A Ilusão Especular: Introdução à Fotografia. São Paulo: Brasiliense. 1984.

MURRAY, J. Hamlet no holodeck: o futuro da narrativa no ciberespaço. Tradução de Elissa Daher e Marcelo Cuzziol. São Paulo: Itaú Cultural/UNESP, 2003.

PETROVITS, A.; CANOSSA, A. From M.C. Escher to Mass Effect: impossible spaces and hyper-real worlds in video games. How can hyper-real worlds be designed and interpreted in a 2D, 2.5D and $3 \mathrm{D}$ virtual environment and how will this implementation affect the stereoscopic $3 \mathrm{D}$ video games of the future? Games as Art, Media, Entertainment. The Italian Journal of Game Studies. 2/2013.

TASSINARI, A. Einstein e a modernidade. Novos estudos - CEBRAP, v. 75, p. 157-170, 2006. 